\title{
Prevalence and Correlates of Mental Distress Among Working Adults in Ethiopia
}

\author{
Bizu Gelaye ${ }^{1,2, *}$, Seblewengel Lemma ${ }^{3}$, Negussie Deyassa ${ }^{4}$, Yonas Bahretibeb ${ }^{4}$, Markos Tesfaye ${ }^{5}$, \\ Yemane Berhane ${ }^{3}$ and Michelle A. Williams ${ }^{1}$ \\ ${ }^{I}$ Department of Epidemiology, Harvard School of Public Health, Boston, MA, USA \\ ${ }^{2}$ Department of Epidemiology, University of Washington School of Public Health, Seattle, WA, USA \\ ${ }^{3}$ Addis Continental Institute of Public Health, Addis Ababa, Ethiopia \\ ${ }^{4}$ Faculty of Medicine, Addis Ababa University, Addis Ababa, Ethiopia \\ ${ }^{5}$ Department of Psychiatry, Jimma University, Jimma, Ethiopia
}

\begin{abstract}
Objective: To evaluate the prevalence of mental distress and its correlates among working Ethiopian adults.
Methods: This cross-sectional study of 2,180 individuals (1,316 men and 864 women) was conducted among working adults in Addis Ababa, Ethiopia. A structured questionnaire was used to collect information on socio-demographic and lifestyle characteristics of participants. Mental distress was assessed using the self-reporting questionnaire (SRQ). Logistic regression was employed to estimate adjusted odds ratios (OR) and 95\% confidence intervals (95\% CI).

Results: The prevalence of mental distress in the study sample was $17.7 \%$ (25.9\% in women and $12.4 \%$ in men). Younger participants (age $\leq 24$ years) had the highest prevalence of mental distress ( $35.5 \%$ in women and $16.7 \%$ in men). The odds of mental distress was 2.47-fold higher among women as compared with men (OR=2.47, 95\% CI 1.97-3.09). Participants reporting excellent health status had a $50 \%$ reduced odds of mental distress $(\mathrm{OR}=0.47 ; 95 \% \mathrm{CI}: 0.38-0.59)$; and moderate alcohol consumption was associated with a slight increased odds of mental distress (OR=1.26; 95\%CI: 1.00-1.67).

Conclusion: A high prevalence of mental distress was observed among working adults in Ethiopia. Our findings suggest that the workforce institutions should provide targeted prevention and intervention programs to improve the mental health state of their employees. National mental health policy that clearly outlines and addresses mental distress among working adults is also warranted.
\end{abstract}

Keywords: Mental Distress, Ethiopia, Mental Health, Working Adults, SRQ.

\section{INTRODUCTION}

Globally, mental health problems account for $13 \%$ of the total burden of disease, and $31 \%$ of all years lived with disability [1]. Mental illness is both a direct cause of mortality and morbidity and a significant risk factor for adverse health outcomes. The social, economic and health impact of mental illness are far-reaching, where they are associated with excess all-cause mortality [2-4], work related disability [2, 46]. lower quality of life [7] and cardiovascular diseases risk [8-10]. Studies conducted in sub-Saharan Africa show that $20-30 \%$ of primary health clinic attendees present with depressive symptoms and other psychological disorders as the first or secondary reason for seeking medical care [11-13]. Furthermore, mental disorders were also shown to account for $11 \%$ of the total burden of diseases in Ethiopia [14].

Mental distress is a collection of mental problems that may not fall into standard diagnostic criteria and are

*Address correspondence to this author at the Department of Epidemiology, Harvard School of Public Health, 677 Huntington Ave, Kresge 501, Boston, MA 02115 USA; Tel: 617-432-1071; E-mail: bgelaye@hsph.harvard.edu characterized by symptoms of insomnia, fatigue, irritability, forgetfulness, difficulty in concentrating, and somatic complaints [15]. The self-reporting questionnaire (SRQ) is a screening instrument developed by the World Health Organization (WHO) to assess symptoms of mental distress [16]. The instrument has been widely used in community based and health care settings worldwide. Several investigators have used SRQ to evaluate the prevalence of mental distress among adults and adolescents in Ethiopia [17-20]. The first study employing SRQ was conducted by Kortmann [21] in 1988 who reported a $12 \%$ prevalence of mental distress disorders among adults in Addis Ababa. Later, other investigators, primarily assessing community- and hospital-based samples in Ethiopia reported prevalence estimates ranging from $11.7 \%$ to $23.9 \%$ [18-20, 22]. For instance, Kebede et al. reported an $11.7 \%$ prevalence of mental distress among residents of Addis Ababa in their 1994 study [18]. The majority of participants in their study $(72 \%)$ were unemployed. These prevalence estimates are expected to be higher among adults who are working to earn a living and, in doing so, are confronted with various daily stresses [4]. Collectively, available studies showed that low educational attainment, 
female sex, older age, small family size and family history of mental illness as important risk factors of mental distress $[17-20,22]$. While the magnitude of mental distress has been documented in community and hospital based samples, to the best of our knowledge, there are no published reports concerning the prevalence and correlates of mental distress among working Ethiopian adults.

In light of the increasing economic burden among urban dwellers and the scarcity of epidemiologic studies evaluating the magnitude of mental distress among the working force, we conducted this study to estimate the prevalence of mental distress and its correlates among working Ethiopian adults. Results from our study will help in developing evidence based mental health promotion and disease prevention programs that are relevant to working Ethiopians.

\section{MATERIALS AND METHODS}

Subjects for this study were recruited between December 2009 and January 2010 as part of a larger occupational cohort study of non-communicable diseases in Addis Ababa, Ethiopia. Details regarding data collection methods and study procedures have been previously described [23, 24]. The primary objective of the parent study was to evaluate the prevalence and risk factors associated with noncommunicable diseases among working Ethiopian adults.

\section{Data Collection and Variable Specification}

Briefly, study subjects were permanent employees of the Commercial Bank of Ethiopia and teachers in public and government schools of Addis Ababa. A multistage, probabilistic stratified sampling strategy was used to identify and recruit participants. Each participant was interviewed by a trained interviewer in accordance with the WHO STEPwise approach for non-communicable diseases surveillance in developing countries [25]. The approach had three levels: (1) questionnaire to gather demographic and behavioral information, (2) simple physical measurements, and (3) biochemical tests. Some questions were added to supplement the WHO questionnaire reflect on the local context. The modified questionnaire was first written in English and then translated into Amharic by experts and was translated back in to English.

\section{Self-Reporting Questionnaire (SRQ-20)}

To identify mental distress, interviews were performed using the Amharic language version of the SRQ. The SRQ is a 24-item questionnaire developed by the WHO to screen for emotional distress [16]. The original SRQ instrument was designed to screen psychotic (4 items) and non-psychotic (20 items) disorders. Because of the low sensitivity and unreliability of the 4 psychotic items, the 20 items are widely used in epidemiologic studies, hence referred as SRQ-20. The SRQ-20 was translated and validated for use in Ethiopia some two decades ago [21]. The SRQ-20 asks respondents whether, within the 4 weeks before the interview, they had experienced symptoms associated with emotional distress, such as crying, inability to enjoy life, tiredness, and suicidal thoughts. Reliability coefficient Cronbach's $\alpha$ in our study for the SRQ-20 was 0.81 (0.82 among women and 0.79 among men) showing very good internal consistency of the items. The validation study conducted in Addis Ababa suggested different cut off points for general outpatient clinic attendees and urban communities. We used cut off points previously used among residents of Addis Ababa. Those who answered 'yes' to six questions or more on the SRQ-20 were defined as having mental distress [18].

\section{Covariates}

Alcohol consumption was classified into low $(<1$ alcoholic beverage a week), moderate (1-21 alcoholic beverages a week), and high to excessive consumption $(>21$ alcoholic beverages a week) according to the WHO classification [26]. Other variables were categorized as follows: age (years), gender, education ( $\leq$ high school, technical school, $\geq$ bachelors), smoking history (never, current, former), and current khat consumption (an evergreen plant with amphetamine-like effects commonly used as a mild stimulant for social recreation and improve work performance in Ethiopia) [27, 28] (no, yes). Participants were also asked the following question about their self-reported health status: "Would you say your health in general is excellent, very good, good, fair, or poor?" We compared those who reported fair or poor health with those who reported excellent, very good, or good health (here in after referred as excellent).

All subjects provided informed consent and the research protocol was approved by the Institutional Review Boards of Addis Continental Institute of Public Health, Addis Ababa, Ethiopia, and the Human Subjects Division at the University of Washington, USA.

\section{Data Analysis}

We first examined frequency distributions of sociodemographic and behavioral characteristics of study participants. Prevalence estimates of mental distress across socioeconomic groups were calculated separately for men and women. The distribution of SRQ-20 scores among men and women, as well as the prevalence of each specific symptom were also estimated. We used multivariable logistic regression procedures to estimate odds ratios (OR) and 95\% confidence intervals $(95 \% \mathrm{CI})$ for the associations between mental distress and socio-demographic factors. Forward logistic regression modeling procedures combined with the changein-estimate approach were used to select the final models reported in this research [29]. Variables of a priori interest (e.g., age and gender) were forced into final models. All analyses were performed using STATA 10.0 statistical software for windows (Statacorp, College Station, TX, USA). All reported $p$-values are two-sided and deemed statistically significant at $\alpha=0.05$.

\section{RESULTS}

A summary of selected socio-demographic and lifestyle characteristics of study participants is presented in Table $\mathbf{1}$. The majority of participants were between 25 and 34 years of age, unmarried, and to have a college diploma, bachelor's degree, or higher education. Approximately $12 \%$ of men and less than $1 \%$ of women reported that they were heavy drinkers. Similarly, approximately $22.0 \%$ of men and less than $1.0 \%$ of women reported that they were current or former smokers. Khat chewing was reported by $14.0 \%$ of men and $0.8 \%$ of women. Approximately $37.0 \%$ of men and $44.0 \%$ of women reported having a fair or poor health status. 
Table 1. Socio-Demogrpahic Characteristics of the Study Population

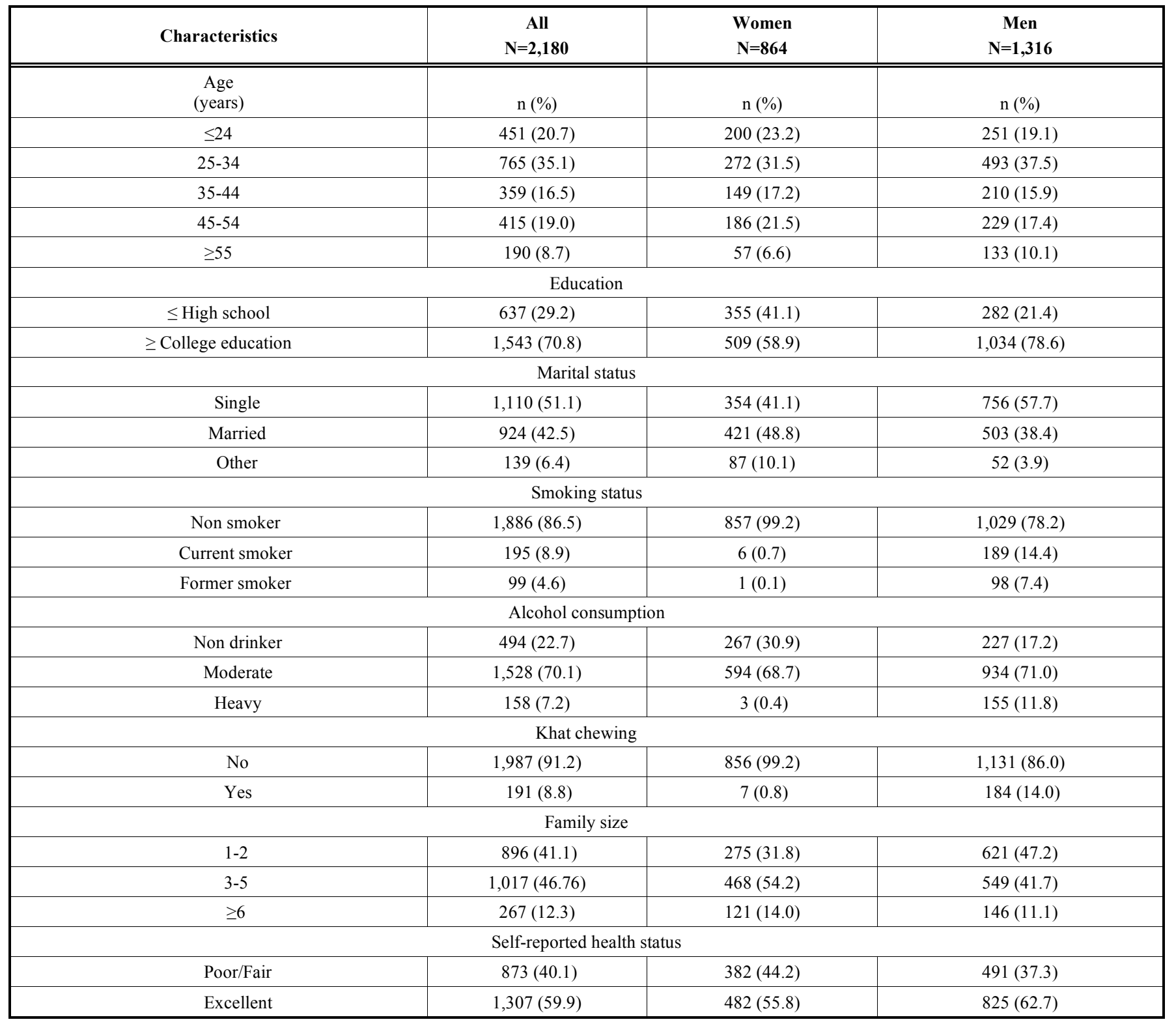

Table 2. Distribution of Positive Answers on each of SRQ-20 Items

\begin{tabular}{|c|c|c|c|}
\hline SRQ-20 Item & $\begin{array}{l}\text { Women } \\
\text { N=864 }\end{array}$ & $\begin{array}{c}\text { Men } \\
\mathbf{N}=1,316\end{array}$ & P-Value \\
\hline Frequent headaches & $292(33.9)$ & $232(17.8)$ & $<0.001$ \\
\hline Poor appetite & $198(23.1)$ & $231(17.7)$ & 0.002 \\
\hline Sleeping badly & $180(20.9)$ & $231(17.7)$ & 0.06 \\
\hline Easily startled & $261(30.3)$ & $143(10.9)$ & $<0.001$ \\
\hline Hands shake & $81(9.4)$ & $110(8.4)$ & 0.421 \\
\hline Nervous, tense or worried & $220(25.6)$ & $204(15.6)$ & $<0.001$ \\
\hline Poor digestion & $315(36.7)$ & $389(29.8)$ & 0.001 \\
\hline Having trouble thinking clearly & $94(10.9)$ & $111(8.5)$ & 0.058 \\
\hline Feeling sadness & $204(23.8)$ & $218(16.7)$ & $<0.001$ \\
\hline Crying in unusual way & $101(11.8)$ & $41(3.1)$ & $<0.001$ \\
\hline
\end{tabular}


Table 2. contd...

\begin{tabular}{|c|c|c|c|}
\hline SRQ-20 Item & $\begin{array}{c}\text { Women } \\
\text { N=864 }\end{array}$ & $\begin{array}{c}\text { Men } \\
\text { N=1,316 }\end{array}$ & $192(14.7)$ \\
\hline \hline Daily work suffering & $133(15.5)$ & $289(22.2)$ & 0.616 \\
\hline Difficulty in reaching decision & $244(28.4)$ & $90(6.9)$ & 0.001 \\
\hline Problem in engaging in day to day activities & $75(8.7)$ & $122(9.4)$ & $108(8.3)$ \\
\hline Unable to play useful part in life & $97(11.3)$ & $37(2.8)$ & 0.120 \\
\hline Lost interest in things & $109(12.7)$ & $25(1.9)$ & 0.146 \\
\hline Feeling worthless & $41(4.8)$ & $144(11.0)$ & 0.001 \\
\hline Having suicidal ideation & $22(2.6)$ & $436(33.5)$ & $185(14.2)$ \\
\hline Feeling tired all the time & $146(16.9)$ & $<0.001$ \\
\hline Uncomfortable feelings in stomach & $255(29.6)$ & $<0.063$ \\
\hline Easily tired & $196(22.8)$ & $<16$ \\
\hline
\end{tabular}

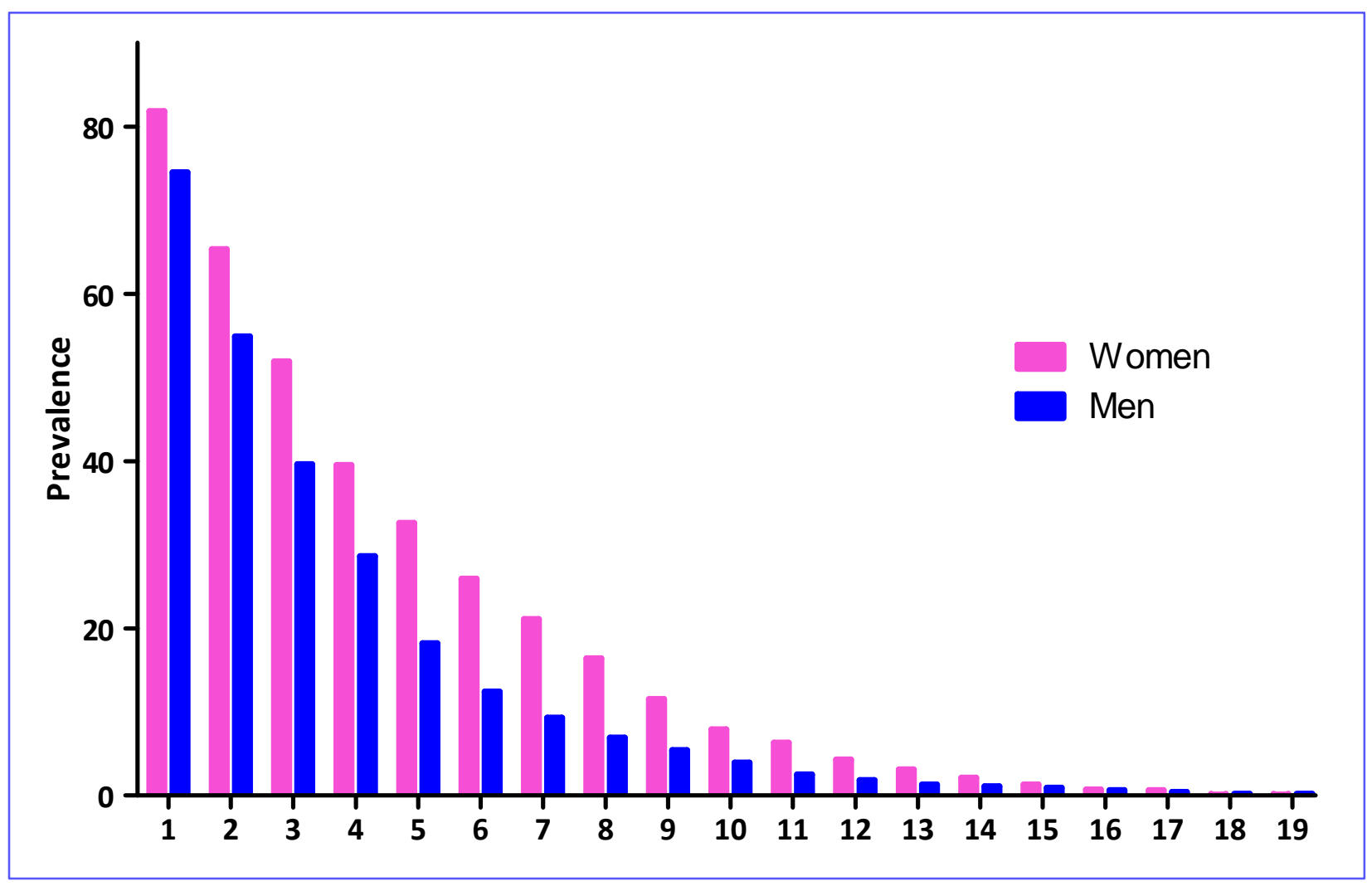

Fig. (1). Prevalence of SRQ-20 Using Different Cut-Points for Mental Distress by Gender.

Table 2 shows the prevalence of specific SRQ-20 symptoms among men and women. Overall, women had significantly higher prevalence of all mental distress symptoms compared with men. Poor digestion $(36.7 \%)$ and frequent headache $(33.9 \%)$ were the most common symptoms reported among women while having uncomfortable feelings in stomach $(33.5 \%)$ and poor digestion $(29.8 \%)$ were more common symptoms experienced by men. Having feelings of suicidal ideation was the least common symptom among women (2.6\%) and men (1.9\%).

Fig. (1) summarizes the prevalence of mental distress for different SRQ-20 cut points for men and women, respec- tively. At the cut-off point of 6 , we identified 387 cases of mental distress, yielding a prevalence of $17.7 \%$ for the total sample. The prevalence of mental distress was $25.9 \%$ in women and $12.4 \%$ in men. If lower cut-off points were used, the prevalence of mental distress would increase by at least 1.5 times at each lower threshold score.

The prevalence of mental distress across the different age groups by gender is summarized in Fig. (2). Younger participants (age $\leq 24$ years) had the highest prevalence of mental distress $(35.5 \%$ in women and $16.7 \%$ in men). Women were more likely to have higher prevalence estimates compared with men across all age groups. 


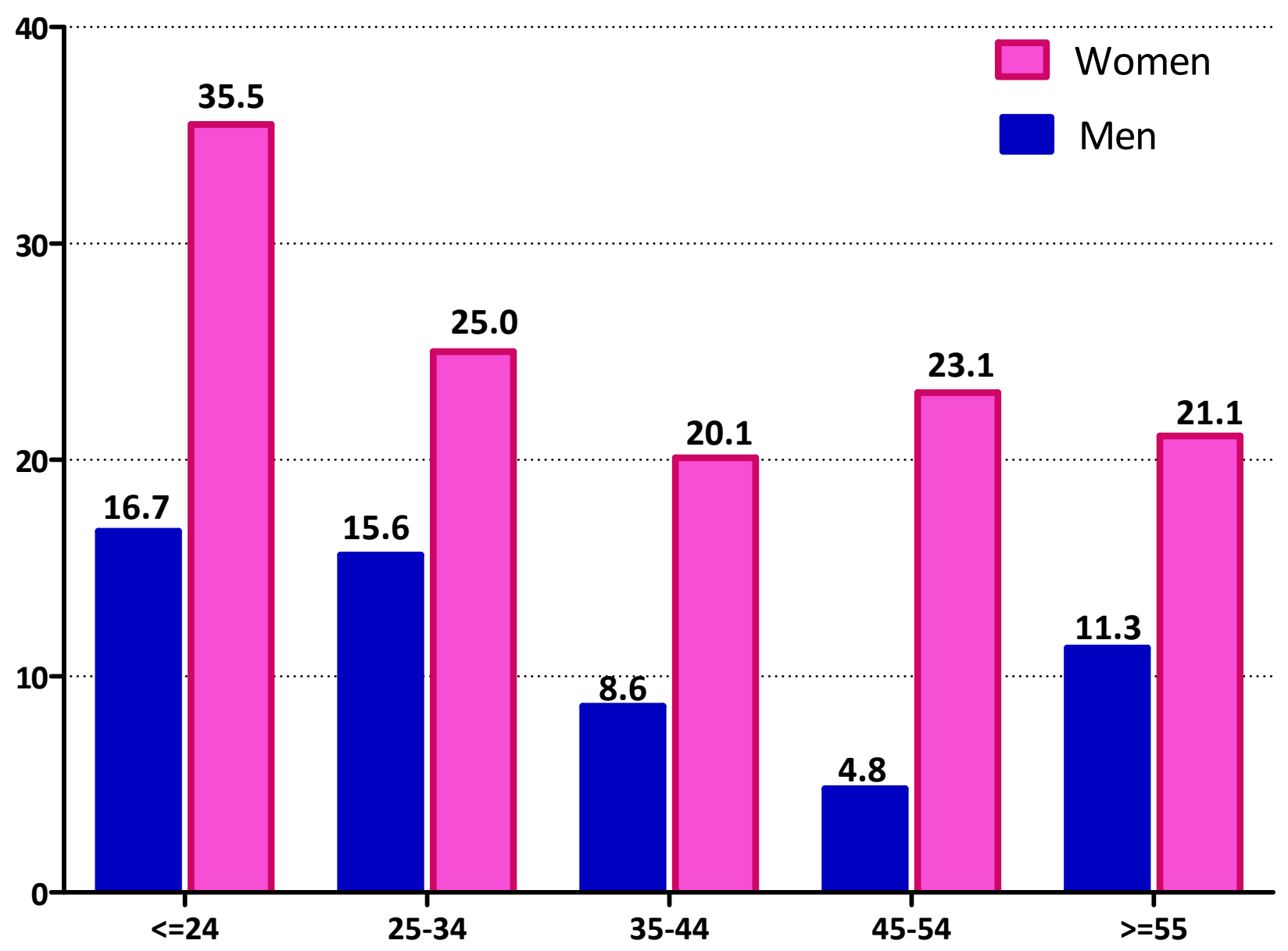

Fig. (2). Prevalence of Mental Distress by Participant Age and Gender.

Table 3. Odds Ratio (OR) and 95\% Confidence Interval (CI) for Mental Distress

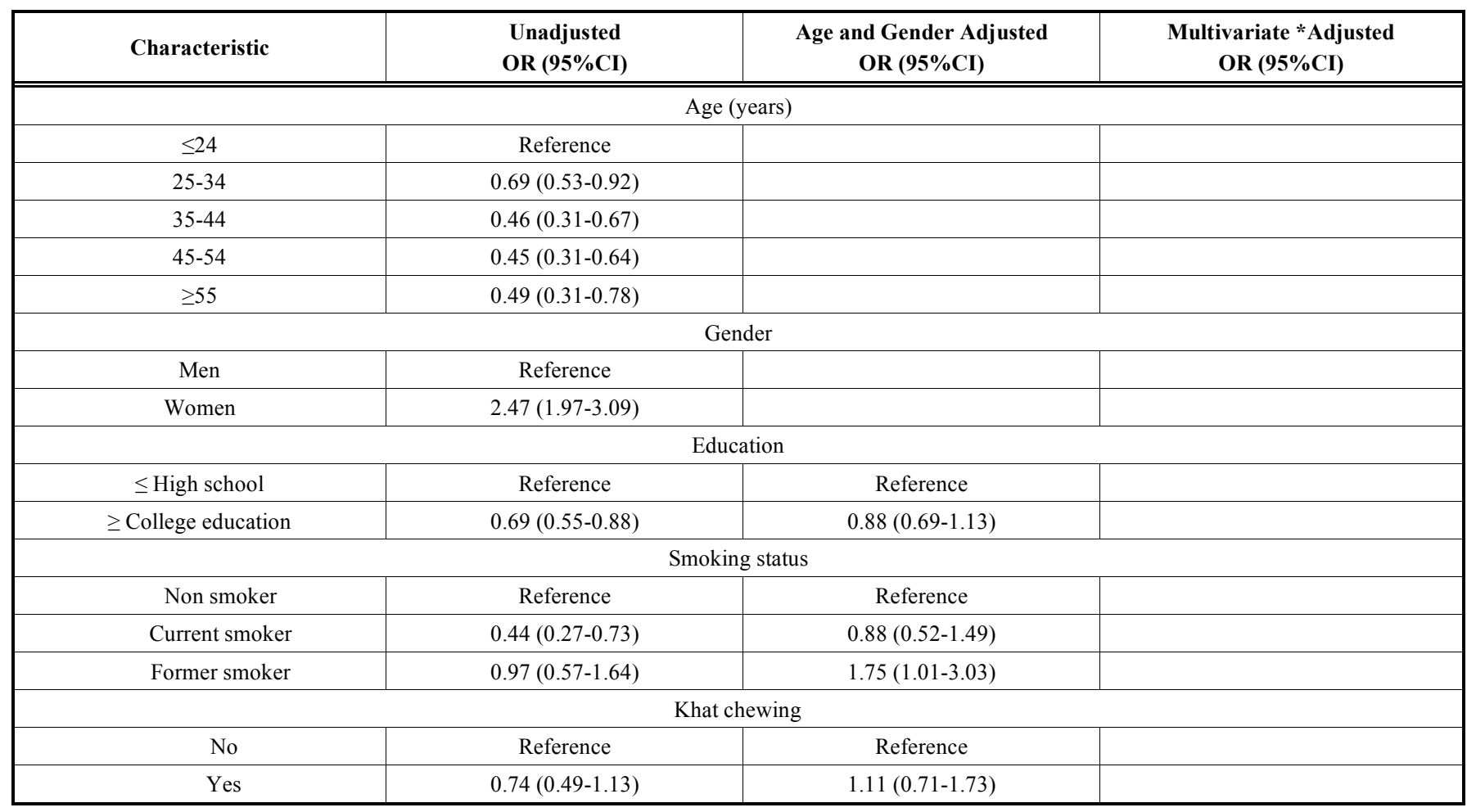


Table 3. contd...

\begin{tabular}{|c|c|c|c|}
\hline Characteristic & $\begin{array}{c}\text { Unadjusted } \\
\text { OR }(95 \% \mathrm{CI})\end{array}$ & $\begin{array}{c}\text { Age and Gender Adjusted } \\
\text { OR }(95 \% \mathrm{CI})\end{array}$ & $\begin{array}{l}\text { Multivariate *Adjusted } \\
\text { OR }(95 \% \mathrm{CI})\end{array}$ \\
\hline \multicolumn{4}{|c|}{ Family size } \\
\hline $1-2$ & Reference & Reference & \\
\hline $3-5$ & $1.15(0.91-1.46)$ & $1.08(0.84-1.39)$ & \\
\hline$\geq 6$ & $1.40(1.00-1.98)$ & $1.31(0.91-1.87)$ & \\
\hline \multicolumn{4}{|c|}{ Marital status } \\
\hline Single & Reference & Reference & Reference \\
\hline Married & $0.60(0.46-0.76)$ & $0.67(0.48-0.92)$ & $0.70(0.50-0.97)$ \\
\hline Other & $1.15(0.75-1.75)$ & $1.21(0.73-2.01)$ & $1.29(0.77-2.19)$ \\
\hline \multicolumn{4}{|c|}{ Alcohol consumption } \\
\hline Non drinker & Reference & Reference & Reference \\
\hline Moderate & $1.08(0.83-1.42)$ & $1.32(1.01-1.74)$ & $1.26(1.00-1.67)$ \\
\hline Heavy & $0.74(0.44-1.23)$ & $1.39(0.81-2.39)$ & $1.22(0.69-2.15)$ \\
\hline \multicolumn{4}{|c|}{ Self-reported health status } \\
\hline Poor/Fair & Reference & Reference & Reference \\
\hline Excellent & $0.47(0.38-0.59)$ & $0.47(0.38-0.59)$ & $0.47(0.37-0.59)$ \\
\hline
\end{tabular}

* Each odds ratio is adjusted for age, gender, occupation and all other covariates listed in the table using forward logistic regression

As shown in Table 3, mental distress decreased with age (p-trend $<0.001$ ). The odds of mental distress was 2.47 -fold higher among women as compared with men $(\mathrm{OR}=2.47$, 95\% CI 1.97-3.09). After adjusting for age and gender former smokers were almost 2-times as likely $(\mathrm{OR}=1.75$; 95\% $\mathrm{CI}: 1.01-3.03$ ) to report mental distress compared with non-smokers. In the multivariate adjusted model participants reporting excellent health status had a $50 \%$ reduced odds of mental distress $(\mathrm{OR}=0.47$; 95\%CI: $0.38-0.59)$; and moderate alcohol consumption was associated with a slight increased odds of mental distress (OR=1.26; 95\%CI: 1.00-1.67). Similar increased odds of mental distress were observed for heavy alcohol consumption $(\mathrm{OR}=1.22$; 95\%CI: $0.69-2.15)$ although statistical significance was not achieved in part due to relatively limited sample size. Married subjects had $30 \%$ reduced odds of mental distress $(\mathrm{OR}=0.70$; 95\%CI: 0.50 0.97 ) as compared with their unmarried counterparts.

\section{DISCUSSION}

The results of this study confirm and expand the literature. First, our study findings confirm a high prevalence mental distress (17.7\%). Importantly, women were more than twice as likely report mental distress as compared with men $(\mathrm{OR}=2.47$; 95\% CI: 1.97-3.09). As expected, women were also more likely to have higher prevalence estimates compared with men across all age groups. Our findings are consistent with prior reports in the literature [17, 18].

Our findings showing high prevalence estimates of mental distress among women compared with men are consistent with most previous studies [17, 18, 30]. Investigators have shown that mental health problems particularly depression, anxiety and somatic complaints affect women to a greater extent than men across diverse societies and social contexts $[31,32]$. Pressures created by their multiple roles and responsibilities, gender discrimination and associated factors such as gender based violence; contribute to women's poor mental health [31-33]. Research has shown that women's subordinate social status is reinforced in the workplace as they are more likely to occupy insecure, low status jobs with no decision making authority [31]. In order to combat these pervasive problems, there is a need to develop and implement policies that empower working women. Working women in developing countries are reported to express their stress and depression through symptoms that closely resemble those commonly found among women in developed countries [34, 35]. A study conducted by Carta et al. [34] in rural Malawi utilizing SRQ-20 showed that social circumstances and type of employment among women influenced psychological conditions and their expression. Importantly, competitive working activities played a role in modifying lifestyle of women and hence contributing to more stress and depression expression [34]. In addition, men may have stoic attitude that limits disclosure of psychological symptoms such as crying. Future research is also needed to fully appreciate the impact of mental distress on work productivity and to elucidate how the gender differences in mental distress might influence reproductive and other health outcomes.

Our finding concerning the association between younger age and mental distress is not in agreement with some previous reports $[17,18]$. For instance Alem et al. in their study among semi-urban population in Butajira found a positive association between older age and mental distress [17]. The authors speculated that older subjects were more likely to have an accumulation of stressful life events and biological changes as age progresses. Whereas, Kessler et al. in their National Comorbidity Survey in the United States, found old age to be a protective factor for all psychiatric diagnoses [36]. We hypothesize that younger study subjects in our study might have life stressors due to adjustment to the work environment during the first few years and increased economic burden compared with older subjects. This hypothesis is corroborated by a study of medical students of Addis 
Ababa University which documented a $32.6 \%$ prevalence of mental distress [22]. Furthermore investigators noted that high rates of common mental disorders in developing countries are attributed, in part, to living through a period of rapid social changes [37].

Our findings are generally consistent with studies documenting positive associations between alcohol consumption and mental distress [18] although there is no consensus as to whether increased alcohol consumption precedes, or is a consequence of, mental health problems [38, 39]. Nevertheless, available evidence suggest that small reductions in alcohol consumption improves mental health [40]. In this study, we found that married participants were $30 \%$ less likely to have mental distress compared with their unmarried counterparts. This finding is not in agreement with a previous study that reported increased mental distress among married participants $(\mathrm{OR}=1.66 ; 95 \% \mathrm{CI}: 1.39-2.00)$ compared with unmarried participants in rural and semi urban community based settings in Ethiopia [17]. However, Kessler et al reported marital disruption was associated with increased mental disorder [36]. We do not have a clear explanation for this. It may be that those who are married are more likely to have settled and share the burden of increasing living cost and more positive health behaviors that may contribute to reduced mental distress [41].

Some important limitations must be considered when interpreting the results of our study. First, the cross-sectional study design precludes delineation of the temporal relation between correlates and mental distress. Second, mental distress is based on self-report and thus, is subject to nonsystematic errors in recall and systematic nondisclosure. Both types of errors may have led to some misclassification in our study. Finally, study findings may not be generalized to the broader Ethiopian population since our study was limited to largely well-educated, urban dwelling, employed professionals in banking and academic sectors.

Despite differences in study subject characteristics and different cut-off points used to define mental distress, our study findings are in general agreement with previous reports that documented higher prevalence estimates in Ethiopia [17, 18]. To the best of our knowledge; this is the first reported study among working Ethiopian adults.

Although any employment has been suggested to be protective against mental distress [42], results from this study indicate high prevalence of mental distress among working adults. Our study is an important contribution to research focused on guiding the prevention of mental distress among working adults in Ethiopia. Our findings suggest that the workforce institutions should provide a broad range of targeted prevention and intervention programs to improve the mental health state of their employees. The impact of mental health on productivity and its co-morbidity with other chronic and infectious diseases make mental health promotion in lowincome countries a necessity - far from luxury as it is often portrayed [37, 43]. In Ethiopia, significant strides have been made over the past two decades by a handful of visionary and courageous psychiatric epidemiologists in bringing mental illness issues in to light $[44,45]$. Their work, in part, has brought important changes in expanding mental health service and training in the country. Despite these laudable changes over the past few years, much remains to be done to put mental health high in the national public health policy agenda and priority. The economic and social impacts of mental health problems are detrimental at individual, societal, institutional and national level. Policy makers at all level should engage mental health experts in current and future health systems strengthening efforts.

\section{CONFLICT OF INTEREST}

The authors confirm that this article content has no conflicts of interest.

\section{ACKNOWLEDGEMENT}

This research was supported by an award from the National Institutes of Health, National Institute of Minority Health and Health Disparities (T37-MD001449). The authors wish to thank the staff of Addis Continental Institute of Public Health for their expert technical assistance.

\section{REFERENCES}

[1] WHO: The Global Burden of Disease 2004 Update. Geneva, Switzerland 2004

[2] Mogga S, Prince M, Alem A, et al. Outcome of major depression in Ethiopia: population-based study. Br J Psychiatry 2006; 189: 2416.

[3] Wild LG, Flisher AJ, Lombard C. Suicidal ideation and attempts in adolescents: associations with depression and six domains of selfesteem. J Adolesc 2004; 27(6): 611-24.

[4] Gureje O, Kola L, Afolabi E. Epidemiology of major depressive disorder in elderly Nigerians in the Ibadan Study of Ageing: a community-based survey. Lancet 2007; 370(9591): 957-64.

[5] Bolton P, Neugebauer R, Ndogoni L. Prevalence of depression in rural Rwanda based on symptom and functional criteria. J Nerv Ment Dis 2002; 190(9):631-7.

[6] Jelsma J, Mielke J, Powell G, De Weerdt W, De Cock P. Disability in an urban black community in Zimbabwe. Disabil Rehabil 2002; 24(16): 851-9.

[7] Mosaku KS, Fatoye FO, Komolafe M, Lawal M, Ola BA. Quality of life and associated factors among adults with epilepsy in Nigeria. Int J Psychiatry Med 2006; 36(4): 469-81.

[8] Gromova HA, Gafarov VV, Gagulin IV. Depression and risk of cardiovascular diseases among males aged 25-64 (WHO MONICA--psychosocial). Alaska Med 2007; 49(2 Suppl): 255-8.

[9] Jonas BS, Franks P, Ingram DD. Are symptoms of anxiety and depression risk factors for hypertension? Longitudinal evidence from the National Health and Nutrition Examination Survey I Epidemiologic Follow-up Study. Arch Fam Med 1997; 6(1): 43-9.

[10] Kinder LS, Carnethon MR, Palaniappan LP, King AC, Fortmann SP. Depression and the metabolic syndrome in young adults: findings from the Third National Health and Nutrition Examination Survey. Psychosom Med 2004; 66(3): 316-22.

[11] Ngoma MC, Prince M, Mann A. Common mental disorders among those attending primary health clinics and traditional healers in urban Tanzania. Br J Psychiatry 2003; 183: 349-55.

[12] Abbo C, Ekblad S, Waako P, Okello E, Musisi S. The prevalence and severity of mental illnesses handled by traditional healers in two districts in Uganda. Afr Health Sci 2009; 9 Suppl 1: S16-22.

[13] Flisher AJ, Lund C, Funk $\mathrm{M}$, et al. Mental health policy development and implementation in four African countries. J Health Psychol 2007; 12(3): 505-16.

[14] Abdulahi H, Mariam DH, Kebede D. Burden of disease analysis in rural Ethiopia. Ethiop Med J 2001; 39(4): 271-81.

[15] Goldberg DP, Huxley P. Common mental disorders : a bio-social model. London; New York: Tavistock/Routledge; 1992.

[16] WHO: A user's guide to the self-reporting questionnaire (SRQ). Geneva, Switzerland 1994.

[17] Alem A, Kebede D, Woldesemiat G, Jacobsson L, Kullgren G. The prevalence and socio-demographic correlates of mental distress in Butajira, Ethiopia. Acta Psychiatr Scand Suppl 1999; 397: 48-55. 
[18] Kebede D, Alem A, Rashid E. The prevalence and sociodemographic correlates of mental distress in Addis Ababa, Ethiopia. Acta Psychiatr Scand Suppl 1999; 397: 5-10.

[19] Tesfaye A. Prevalence and correlates of mental distress among regular undergraduate students of Hawassa University: a cross sectional survey. East Afr J Public Health 2009; 6(1): 85-94.

[20] Tadesse B, Kebede D, Tegegne T, Alem A. Childhood behavioural disorders in Ambo district, western Ethiopia. I. Prevalence estimates. Acta Psychiatr Scand Suppl 1999; 397: 92-7.

[21] Kortmann F. Problems in practising psychiatry in Ethiopia. Ethiop Med J 1988; 26(2): 77-84.

[22] Alem A, Araya M, Melaku Z, Wendimagegn D, Abdulahi A. Mental distress in medical students of Addis Ababa University. Ethiop Med J 2005; 43(3): 159-66.

[23] Wai WS, Dhami RS, Gelaye B, et al. Comparison of Measures of Adiposity in Identifying Cardiovascular Disease Risk Among Ethiopian Adults. Obesity (Silver Spring) 2012; 20(9): 1887-95.

[24] Tran A, Gelaye B, Girma B, et al. Prevalence of Metabolic Syndrome among Working Adults in Ethiopia. Int $\mathrm{J}$ Hypertens 2011;2011:193719.

[25] WHO: STEPs manual. Geneva: World Health Organization; 2008.

[26] WHO: Global status report on alcohol. Geneva, Switzerland: World Health Organization. Department of Mental Health and Substance Abuse; 2004.

[27] Belew M, Kebede D, Kassaye M, Enquoselassie F. The magnitude of khat use and its association with health, nutrition and socioeconomic status. Ethiop Med J 2000; 38(1): 11-26.

[28] Kalix P: Khat. scientific knowledge and policy issues. Br J Addict 1987; 82(1): 47-53.

[29] Rothman KJ, Greenland S. Modern epidemiology. Philadelphia: Lippincott-Raven 1998.

[30] Richardson LK, Amstadter AB, Kilpatrick DG, et al. Estimating mental distress in Vietnam: the use of the SRQ-20. Int J Soc Psychiatry 2010; 56(2): 133-42.

[31] WHO: Gender disparities in mental health. World Health Organization. Department of Mental Health, and Substance Dependence. Geneva, Switzerland 2002.

[32] Gelaye B, Arnold D, Williams MA, Goshu M, Berhane Y. Depressive Symptoms Among Female College Students Experiencing Gender-Based Violence in Awassa, Ethiopia. J Interpers Violence 2009; 24(3): 464-81.
[33] Krieger N, Waterman PD, Hartman C, et al Social hazards on the job: workplace abuse, sexual harassment, and racial discrimination-a study of Black, Latino, and White low-income women and men workers in the United States. Int J Health Serv 2006; 36(1): 51-85.

[34] Carta MG, Carpiniello B, Dazzan P, Reda MA. Depressive symptoms and occupational role among female groups: a research in a south-east African village. Psychopathology 2000; 33(5): 2405.

[35] Carta MG, Coppo P, Reda MA, Hardoy MC, Carpiniello B. Depression and social change. From transcultural psychiatry to a constructivist model. Epidemiol Psichiatr Soc 2001; 10(1): 46-58.

[36] Kessler RC, Berglund P, Demler O, Jin R, Merikangas KR, Walters EE. Lifetime prevalence and age-of-onset distributions of DSM-IV disorders in the National Comorbidity Survey Replication. Arch Gen Psychiatry 2005; 62(6): 593-602.

[37] Patel V, Kleinman A. Poverty and common mental disorders in developing countries. Bull World Health Organ 2003; 81(8): 60915 .

[38] Kessler RC, Nelson CB, McGonagle KA, Edlund MJ, Frank RG, Leaf PJ. The epidemiology of co-occurring addictive and mental disorders: implications for prevention and service utilization. Am J Orthopsychiatry 1996; 66(1):17-31.

[39] Merikangas KR, Mehta RL, Molnar BE, et al. Comorbidity of substance use disorders with mood and anxiety disorders: results of the International Consortium in Psychiatric Epidemiology. Addict Behav 1998; 23(6): 893-907

[40] WHO: Mental health and development: targeting people with mental health conditions as a vulnerable group. Geneva, Switzerland. 2010.

[41] Robles TF, Kiecolt-Glaser JK. The physiology of marriage: pathways to health. Physiol Behav. 2003; 79(3): 409-16

[42] Leekassa R, Bizuneh E, Alem A. Prevalence of mental distress in the outpatient clinic of a specialized leprosy hospital. Addis Ababa, Ethiopia, 2002. Lepr Rev 2004; 75(4): 367-75.

[43] Herrman H, Swartz L. Promotion of mental health in poorly resourced countries. Lancet 2007; 370(9594): 1195-7.

[44] Giel R. The prehistory of psychiatry in Ethiopia. Acta Psychiatr Scand Suppl 1999; 397: 2-4.

[45] Alem A. Mental health services and epidemiology of mental health problems in Ethiopia. Ethiop Med J 2001; 39(2): 153-65.

(C) Gelaye et al.; Licensee Bentham Open.

This is an open access article licensed under the terms of the Creative Commons Attribution Non-Commercial License (http://creativecommons.org/licenses/by-nc/3.0/) which permits unrestricted, non-commercial use, distribution and reproduction in any medium, provided the work is properly cited. 